East African Medical Journal Vol. 81 No. 3 March 2004

COMPARATIVE EFFICACY OF ALBENDAZOLE AND THREE BRANDS OF MEBENDAZOLE IN THE TREATMENT OF ASCARIASIS AND TRICHURIASIS

M. Legesse, MSc, Immunoparasitologist, B. Erko, MSc, Parasitologist and G. Medhin, MSc, Biostatistician, Institute of Pathobiology, Addis Ababa University, P.O. Box 1176, Addis Ababa, Ethiopia

Request for reprints to: M. Legesse, Institute of Pathobiology, Addis Ababa University, P. O. Box 1176, Addis Ababa, Ethiopia.

\title{
COMPARATIVE EFFICACY OF ALBENDAZOLE AND THREE BRANDS OF MEBENDAZOLE IN THE TREATMENT OF ASCARIASIS AND TRICHURIASIS
}

\author{
M. LEGESSE, B. ERKO and G. MEDHIN
}

\begin{abstract}
Objective: To evaluate the comparative efficacy of $400 \mathrm{mg}$ albendazole (Smith Kline Beecham) as a single dose and three brands of mebendazole (Janssen, Unibios and East African Pharmaceuticals) at doses of $\mathbf{1 0 0} \mathbf{~ m g}$ twice a day for three consecutive days in the treatment of single or mixed infections with Ascaris lumbricoides and or Trichuris trichiura in four treatment groups of school children.

Design: Randomized trial.

Setting: Wondo-Genet, southern Ethiopia.

Subjects: School children, aged six to nineteen years.

Results: The percentage cure rate and egg reduction rate obtained with albendazole and mebendazole from the three brands were not significantly different in the treatment of ascariasis. However, significant differences were found among the percentage cure rates and egg reduction rates of the four treatment groups in the treatment of trichuriasis. Comparatively, high cure rate $(\mathbf{8 9 . 8 \%})$ and egg reduction rate $\mathbf{( 9 9 . 1 \% )}$ ) were observed in vermox (Janssen) treated group followed by Unibios (India) treated group $(53.3 \%$ and $96.53 \%$ cure and egg reduction rates, respectively), whereas low cure rate $(17.1 \%)$ and egg reduction rate $(69.8 \%)$ were seen in the albendazole treated group.

Conclusion: The results of this study suggest that in areas of single or mixed infections with Trichuris trichiura and/or Ascaris lumbricoides are common public health problems and where laboratory facilities are not available to make parasite identification, mebendazole (particularly vermox, a product of Janssen laboratory) would be the drug of choice to treat trichuriasis and ascariasis. However, either mebendazole from the different brands or albendazole is effective in the treatment of ascariasis in areas where trichuriasis is not prevalent.
\end{abstract}

\section{INTRODUCTION}

Infection with intestinal helminths is one of the most common health problems of children in developing countries. Moreover, chronic intestinal helminthic infections have been identified as one of the possible risk factors that contribute to the pathogenesis as well as the widespread of other infectious agents such as HIV and mycobacterium in the tropical countries(1-4).

In developing countries, it is difficult to prevent infection with geo-helminths because improvements in environmental sanitation are not easily achievable. However, treatment of infected individuals with effective and broad-spectrum anthelminitics can minimise problems that arise from intestinal helminthic infections $(5,6)$.

Several studies have shown that albendazole and mebendazole from different brands are drugs of choices for the treatment of single or mixed infections with intestinal helminths(7-10). In contrast, others have reported that these drugs are not equally effective in curing all intestinal helminthic infections(11-15).
Few studies have directly compared the efficacies of mebendazole from different brands or efficacy of albendazole to that of mebendazole from different brands in the treatment of intestinal helminths using the recommended dosages by the manufacturers $(12,16)$.

In the present study, comparative efficacy of three brands of mebendazole (i.e. Janssen, Unibios and East African Pharmaceuticals) and albendazole (Smith Kline Beecham) was assessed in Wondo-Genet, southern Ethiopia, against the most common geo-helminths, Ascaris lumbricoides and Trichuris trichiura.

\section{MATERIALS AND METHODS}

Study Area: The trial was conducted in Wondo-Genet, southern Ethiopia, in March 2003. Wondo-Genet is a district located some $270 \mathrm{~km}$ south of Addis Ababa at an altitude of about $1800 \mathrm{~m}$ above sea level. Majority of inhabitants of Wondo-Genet belong to the Sidama ethnic group and chiefly earn their living as farmers practicing settled mixed agriculture. Enset and maize are the principal food crops produced while 
sugar cane and chat (Catha edulis) are the principal cash crops of the area. Ascaris lumbricoides, Trichuris trichiura and Schistosoma mansoni are the three most prevalent intestinal helminths in the area (Berhanu Erko, Institute of Pathobiology, personal communication).

Study population: A cross-sectional parasitological survey was conducted in two schools (Shesha Kekel and Wondo Wosha) to identify positive subjects to be randomised into four treatment arms. In the survey, stool specimens were collected from 730 children ( 387 males and 343 females) age ranged from six to nineteen years. After examining the stool specimens all subjects positive for Ascaris lumbricoides and/ or Trichuris trichiura infections were randomised into four groups.

Sample size determination: Sample size for this trial was estimated in such a way that the study would attain power of $80 \%$ to $85 \%$ and estimation of effects with $90 \%$ to $95 \%$ confidence levels. The following additional assumptions were also used as inputs to sample size calculation(1). In the treatment of trichuris infection cure rate of each brand of mebendazole was assumed to be $37 \%$ while cure rate of albendazole was assumed to be significantly less than $37 \%$ taking $15 \%$ as minimum detectable difference(2). That each drug to be used in this trial would result in at least $94 \%$ cure rate with minimum detectable difference of $6 \%$ in the treatment of ascaris infection. Hence, about 148 students positive for each of the two target parasites ( i.e. Ascaris and Trichuris) per treatment group (i.e. about 608 students in total) were sufficient for the trial.

Stool collection and examination: After giving adequate instruction on how to provide stool samples, small pieces of plastic sheets were distributed to the study subjects to provide sizeable fresh stool specimens of their own. The specimens were processed using Kato technique employing a template delivering a plug of $41.7 \mathrm{mg}$ of stool as previously described(17) and microscopically examined for eggs of intestinal helminths by two senior laboratory technicians. Egg count was performed for Ascaris lumbricoides and Trichuris trichiura.

Drugs: Albendazole (Smith Kline Beecham, France), vermox (Janssen, South Africa) and mebendazole (Unibios, India) were purchased from local pharmacies. Mebendazole, a product of East African pharmaceuticals (Ethiopia), was kindly donated by Dr. A.R. Hashim, Manager of East African pharmaceuticals in Addis Ababa.

Treatment allocation: A sequentially numbered list of students positive for at least one of the two helminth infections (ascariasis or trichuriasis) was prepared and randomly divided into four treatment groups using random numbers obtained from a random number table. Following randomisation, the students were informed the date of treatment through their school teachers. Hence, 661 children showed up on treatment day. On the basis of the random assignment prepared before hand, 197 children were treated with $400 \mathrm{mg}$ of albendazole as a single dose while 144 children, 166 children and 154 children were treated with 100 mg of mebendazole from Unibios, Janssen and East African pharmaceuticals, respectively, twice a day for three consecutive days. The single-dose treatment of albendazole and the first dose of mebendazole were administered under the supervision of a local nurse and the research team. The remaining mebendazole tablets were given to the parents or guardians of the children after giving adequate instruction on the dosage of the drugs. The parents or guardians of the children as well as school teachers verified that the drugs were taken properly. During the initiation of treatment, all children were interviewed whether or not they had received any anthelminthic drugs in the past three months and none of them reported to receive drug treatment during the period in question. Twenty-one days after treatment, faecal samples were collected for efficacy determination.

Ethical considerations: The objective of the study was explained to school teachers and the students at the time of baseline data collection. The stool sample was then collected after obtaining verbal consent. Positive individuals for $S$. mansoni infection were treated with praziquantel at the time of stool collection for efficacy determination.

Statistical analysis: The egg reduction and cure rates of each drug were compared based on their percent of egg count reduction and cure rate using Stata Version 6. Fisher's exact test was used to compare proportions among the study groups. The intensity of infection was determined for Ascaris lumbricoides and Trichuris trichiura and expressed as egg per gram (epg) of faeces for each individual. Geometric mean egg count was estimated as $\exp [1 \mathrm{n}(\mathrm{c}+1) / \mathrm{n}],-1$ where $\mathrm{c}$ was the egg counts (epg) for a particular individual and $n$ is the number of individuals. Intensity of infection was compared using ANOVA. Changes in egg counts within individuals were compared by calculating $D_{i}=\ln \left(c_{0}+1\right)-\ln \left(c_{1} 1\right)$ for each individual, where $1 \mathrm{n}$ is natural logarithm, $\mathrm{c}_{\mathrm{O}}$ is the egg count before treatment, $\mathrm{c}_{1}$ is the egg count after treatment and $\mathrm{Di}$ is the difference for the $\mathrm{i}_{\text {th }}$ individual. Differences among the four treatments were compared using ANOVA and the percentage of egg count reduction induced by the treatment was estimated as $100[1-\exp (-\mathrm{D})] \%$, where D was the mean difference for a particular treatment.

\section{RESULTS}

Of the 730 stool specimens collected, 13 (1.8\%) specimens were not examined because of mislabeling. Of the remaining 717 specimens, 703 (98.0\%) were positive for one or more helminth infections. The most prevalent parasite was Trichuris trichiura (91.0\%) followed by Ascaris lumbricoides (81.4\%), and then by Schistosoma mansoni (55.2\%). Prevalence of taeniasis and entrobiasis was not high (3.1\% and $2 \%$, respectively). Since stool examination was not performed within one hour of sample collection(12), prevalence of hookworm infection was not determined.

Stool specimens were collected from 534 children, 130 albendazole and 404 mebendazole treated (123 Unibios, 138 Janssen and 143 East African pharmaceuticals) 21 days post-treatment to determine the efficacy of each drug on cure and egg reduction rates in ascariasis and trichuriasis. From those who received treatment, 127 children (34.0\%) from albendazole treated group, 11(7.1\%) from East African mebendazole treated group, 21(14.6\%) from Unibios mebendazole treated group and 28(16.9\%) from vermox treated group] did not appear during stool collection for efficacy determination. 
Table 1

Baseline characteristics of the study subjects as randomised into different treated groups

\begin{tabular}{llllll}
\hline Variable & $\begin{array}{l}\text { Alb } \\
(\mathrm{n}=130)\end{array}$ & $\begin{array}{l}\text { EA-meb } \\
(\mathrm{n}=143)\end{array}$ & $\begin{array}{l}\text { Meb } \\
(\mathrm{n}=123)\end{array}$ & $\begin{array}{l}\text { Vermox } \\
(\mathrm{n}=138)\end{array}$ & p-value \\
\hline Sex (\%) & & & & \\
$\quad \begin{array}{l}\text { Male students } \\
\text { Age mean(SD) }\end{array}$ & 55 & 53 & 47 & 54 & 0.715 \\
$\begin{array}{c}\text { Prevalence } \\
\quad \text { Ascariasis }\end{array}$ & $10.5(2.2)$ & $10.1(2.0)$ & $10.9(2.1)$ & $11.1(2.2)$ & 0.000 \\
$\quad \begin{array}{l}\text { Trichuriasis } \\
\begin{array}{l}\text { Intensity (G. mean) } \\
\text { Ascariasis }\end{array}\end{array}$ & 82.3 & 80.4 & 78.9 & 81.9 & 0.919 \\
$\quad$ Trichuriasis & 290.9 & 90.9 & 92.7 & 85.5 & 0.084 \\
\hline
\end{tabular}

$\mathrm{Alb}=$ albendazole, EA-meb = East African mebendazole, Meb = Indian mebendazole (Unibios), and vermox = South African mebendazole (Janssen)

Table 2

Percentage of egg reduction and cure rates obtained with different brands of mebendazole (Janssen, Unibios and East Africa) and albendazole in ascariasis and trichuriasis 21 days post-treatment

\begin{tabular}{|c|c|c|c|c|c|c|c|c|}
\hline \multirow[t]{2}{*}{ Helminth } & \multirow[t]{2}{*}{ Treatment } & \multirow{2}{*}{$\begin{array}{l}\text { No. of } \\
\text { individuals }\end{array}$} & \multicolumn{2}{|c|}{ No. execrating } & \multirow{2}{*}{$\begin{array}{l}\text { Cure } \\
\text { rate }(\%)\end{array}$} & \multirow{2}{*}{$\begin{array}{l}\text { Geom } \\
\text { Bef. tre. }\end{array}$} & \multirow{2}{*}{$\begin{array}{l}\text { Mean } \\
\text { Aft. tret. }\end{array}$} & \multirow{2}{*}{$\begin{array}{c}\text { Egg Reduction } \\
(\%)\end{array}$} \\
\hline & & & Bef. treat. & Aft. tret & & & & \\
\hline \multirow[t]{4}{*}{$\mathrm{Al}$} & vermox & 138 & 113 & 4 & $96.5 \mathrm{a}$ & 8188.9 & 1833.2 & 99.9 \\
\hline & Meb & 123 & 97 & 1 & $99.0 \mathrm{~b}$ & 6925.5 & 384.0 & 99.9 \\
\hline & EA-meb & 143 & 115 & 8 & $93.0 \mathrm{c}$ & 6198.2 & 1295.9 & 99.9 \\
\hline & Alb & 130 & 107 & 89 & 92.5 & 6982.2 & 305.1 & 99.9 \\
\hline \multirow[t]{4}{*}{$\mathrm{Tt}$} & vermox & 138 & 118 & 14 & $89.8 \mathrm{a}^{*}$ & 414.1 & 91.4 & $99.1 *$ \\
\hline & Meb & 123 & 114 & 55 & $53.5 b^{*}$ & 376.4 & 118.1 & $96.5^{*}$ \\
\hline & EA-meb & 143 & 130 & 97 & $27.9 \mathrm{c} *$ & 522.3 & 171.6 & $88.5^{*}$ \\
\hline & Alb & 130 & 123 & 107 & $17.1^{*}$ & 445.7 & 258.0 & $69.8 *$ \\
\hline
\end{tabular}

$\mathrm{a}=$ Vermox compared versus Meb, EA-meb \& Alb, $\mathrm{b}=$ Meb compared versus EA-meb and Alb, $\mathrm{c}=$ EA- meb compared versus Alb. * there were statistically significant differences in cure rates and egg reduction rates of the drugs $(\mathrm{P}<0.05)$. Al $=$ Ascaris lumbricoides, $\mathrm{Tt}=$ Trichuris trichiura, $\mathrm{Alb}=$ albendazole, EA-. meb $=$ East African mebendazole, Meb $=\mathrm{Indian}$ mebendazole (Unibios) and vermox $=$ South African mebendazole (Janssen).

The effect of withdrawal from different treatment groups on baseline data (sex composition, mean age, intensity and prevalence of ascariasis and trichuriasis) was assessed (Table 1). Significant difference was found in the prevalence of trichuriasis among mebendazole (Unibios) treated subjects $(76.2 \%$ among absent versus $92.7 \%$ among present; $\mathrm{p}<0.05)$ and in the percentage of absent and present female students in the albendazole treated group $(27.3 \%$ of females in the absent versus $44.6 \%$ of the females in the present, $\mathrm{p}=0.02$ ).

The number of children excreting eggs of Ascaris lumbricoides and Trichuris trichiura pre-and posttreatment, geometric mean egg count and the overall percentage of egg reduction and cure rates are shown in Table 2. Percentage cure and egg reduction rates obtained with albendazole and mebendazole from the three brands were not significantly different in ascariasis. Significant differences were found among the percentage cure rates as well as egg reduction rates of the four treatment groups in trichuriasis. Comparatively, high cure rate $(89.8 \%)$ and egg reduction rate $(99.1 \%)$ were observed in vermox (Janssen) treated group followed by Unibios (India) treated group (cure and egg reduction rates, $53.3 \%$ and $96.5 \%$, respectively), whereas low cure rate $(17.1 \%)$ and egg reduction rate $(69.8 \%)$ were seen in the albendazole treated group.

\section{DISCUSSION}

In the present study, the comparative efficacy of mebendazole from three brands and albendazole was evaluated against ascariasis and trichuriasis at the dosages recommended by the manufacturers. The results indicated that mebendazole from the three brands (Janssen, Unibios and East African Pharmaceuticals) at doses of $100 \mathrm{mg}$ twice a day for three consecutive days and $400 \mathrm{mg}$ of albendazole (Smith Kline Beecham) as 
a single dose were highly effective against Ascaris lumbricoides and did not differ in egg reduction rates as well as in cure rates. However, they did differ significantly both in egg reduction rates and cure rates in the treatment of trichuriasis although there were no differences among the four treatment groups in the intensity of Trichuris trichiura infection before treatment as determined by egg counts. A previous study in Ethiopia has shown that Indian brand of mebendazole (Unibios) is more effective than albendazole (Smith Kline Beecham, France) in the treatment of single or mixed infections with Ascaris lumbricoides and Trichuris trichiura(16). In the present study, $400 \mathrm{mg}$ single dose of albendazole brought about low egg reduction and cure rates in trichuriasis as compared to multiple doses of mebendazole from the three brands.

The egg reduction rate of $69.8 \%$ obtained with a single dose of $400 \mathrm{mg}$ albendazole in the present study in the treatment of trichuriasis is almost comparable to the previous report from Ethiopia(16), but slightly lower than the egg reduction rates $(73.3 \%$ to $87 \%)$ observed elsewhere with the same dose of albendazole 21 days posttreatment in children infected with Trichuris trichiura $(12,18)$. Cure rate of $17.1 \%$ observed in trichuriasis in this study is somewhat higher than the cure rates observed in previous studies $(12,16)$. However, it is lower than cure rate reported by Rossignol and Maisonneve(18).

A dose of $100 \mathrm{mg}$ mebendazole (vermox a product of Janssen laboratory) twice a day for three consecutive days resulted in cure rates of $70 \%-75 \%$ and egg reduction rates of $97.9 \%$ to $99.3 \%$ in trichuriasis $(7,8)$. Comparable to these pervious reports, treatment of trichuriasis with mebendazole (vermox) resulted in a cure rate of $89.9 \%$ and egg reduction rate of $99.1 \%$, which is significantly higher than the cure and egg reduction rates obtained with mebendazole either from Unibios (India) or East African pharmaceuticals (Ethiopia). In contrast to our observation, Albonico et al. (12) have reported the absence of difference between generic mebendazole (Pharmamed) and original mebendazole (Janssen) at a single dose of $500 \mathrm{mg}$ in curing ascariasis, trichuriasis and hookworm infection. However, generic mebendazole has been reported to be less effective than the original product in the treatment of trichuriasis and hookworm infection(19), which is in agreement with our results.

In conclusion, the present study provides useful information on the comparative efficacy of albendazole and mebendazole from three brands in the treatment of ascariasis and trichuriasis. Nevertheless, the comparative efficacy of these drugs was not assessed against hookworm infection. In areas of single or mixed infections with Trichuris trichiura and Ascaris lumbricoides are common public health problems and where laboratory facilities are not available to make parasite identification, mebendazole (particularly, vermox a product of Janssen laboratory) would be the drug of choice to treat trichuriasis and ascariasis. In areas where trichuriasis is not prevalent, either mebendazole from the different brands or albendazole would be effective in the treatment of ascariasis.

\section{ACKNOWLEDGEMENTS}

To East African pharmaceuticals in Addis Ababa for the donation of their mebendazole brand, to the director, teachers and school children of Wondo Wosha and Shasha Kakel Schools and parents/gurdians of the children for their unfailing co-operation during the study. We also acknowledge the technical staff of medical parastology unit of the institute of pathobiology, Addis Ababa university for their assistance

\section{REFERENCES}

1. Bentwich, Z., Kalinkovich, A. and Weisman, Z. Immune activation is a dominant factor in pathogenesis of African AIDS. Immunol. Today 1995; 16:187-191.

2. Borkow, G. and Bentwich, Z. Eradication of helminthic infections may be essential for successful vaccination against HIV and tuberculoses. Bull. World Hlth org. 2000; 78:1368-1369.

3. Diniz, L. M., Zandonade, E., Dietze, R., Pereira, F.E.L. and Rodrigues, R.R. Do intestinal nematodes increase the risk for multibacillary leprosy? Amer. J. Trop. Med. Hyg. 2001; 65:852-854.

4. Elias, D., Wolday, D., Akuffo, H., Petros, B., Bronner, U. and Britton, S. Effect of deworming on human $\mathrm{T}$ cell responses to mycobacterium antigens in helminth exposed individuals before and after BCG vaccination. Clin. Exp.Immunol. 2001; 123:219-225.

5. Stephenson, L.S., Latham, M.C., Kurz, K.M., Kinoti, S.N. and Brigham, $\mathrm{H}$. Treatment with a single dose of albendazole improves growth of Kenyan school children with hookworm, Trichuris trichiura, and Ascaris lumbricoides infections. Amer. J. Trop. Med. Hyg 1989; 4:78-87.

6. Thein-Hlaing, Than-Saw and Myat-Lay-Kyin. The impact of three-monthly age targeted chemotherapy on Ascaris lumbricoides infection. Trans. Roy. Soc. Trop. Med. Hyg. 1991; 85:519-522.

7. Lionel, N.D.W., Soysa, P., Rajapakse, L. and Aiyathurai, J.E.J. Mebendazole in the treatment of intestinal helminthiasis with special reference to whipworm infection. Amer. J. Trop. Med. Hyg. 1975; 77:75-77.

8. Chavarria, A.P., Swartzwelder, J.C., Villarejos, V.M. and Zeledon, R. Mebendazole, an effective broad-spectrum anthelminitic. Amer. J. Trop. Med. Hyg. 1973; 22:592-595.

9. Ramalingam, S., Sinniah, B. and Krishnan, U. Albendazole, an effective single dose, broad-spectrum anthelminitic drug. Amer. J. Trop. Med. Hyg. 1983; 32:984-989.

10. Muttalib, M.A., Khan, M.U. and Haq, J.A. Single dose regime of mebendazole in the treatment of polyparasitism in children. J. Trop. Med. Hhyg. 1981; 84:159-1560.

11. Hall, A. and Nahar, Q. Albendazole and infections with Ascaris lumbricoides and Trichuris trichiura in children in Bangladesh. Trans. Roy Soc. Trop. Med. Hyg. 1994; 88:110-112.

12. Albonico, M., Smith, P.G., Hall, A., Chwaya, H.M., Alawi, K.S. and Savioli, L. A randomised controlled trial comparing mebendazole and albendazole against Ascaris, Trichuris and hookworm infections. Trans. Roy. Soc. Trop. Med. Hyg. 1994; 88:585-589.

13. Albonico, M., Ramsan, M., Wright, V., Jape, K., Haji, H.J., Taylor, M., Savioli, L. and Bickle, Q. Soil-transmitted 
nematode infections and mebendazole treatment in Mafia Island school children. Ann. Trop. Med. Parasitol. 2002; 96:717-726.

14. De Clercq, D., Sacko, M., Berhnke, J., Gilbert, F., Dorny, P. and Vercruysse, J. Failure of mebendazole in treatment of human hookworm infections in the southern region of Mali. Amer. J Trop. Med. Hyg. 1997; 57:25-30.

15. Ndenecho, L., Ndamukong, K.J. and Matute, M.M. Soil transmitted nematodes in children in Buea Health district of Cameroon. East Afr. Med. J. 2002; 79:442-445.

16. Legesse, M., Erko, B. and Medhin, G. Efficacy of albendazole and mebendazole in the treatment of Ascaris and Trichuris infections. Ethiop. Med. J. 2002; 40:335-343.

17. Birrie, H. and Medhin, G. Comparison of different Kato templates for quantitative faecal egg count of intestinal helminth parasites. Ethio. J. Health. Dev. 1996; 10:129-130.

18. Rossignol, J.F. and Maisonneuve, H. Albendazole: placebocontrolled in 870 patients with intestinal helminthiasis. Trans. Roy. Soc. Trop. Med. Hyg 1983; 77:707-711.

19. Charoenlarp, P., Waikagul, J., Muennoo, C., Srinophakun, S. and Kitayaporn, D. XIII International. Congress for Trop. Med. Malaria (Abstract). 1992; 2:255. 